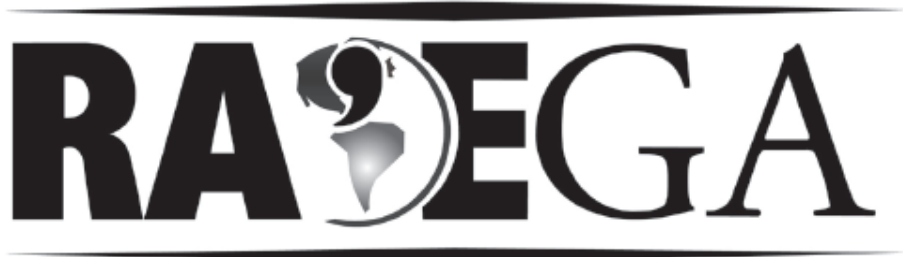

O ESPAÇO GEOGRÁFICO EM ANÁLISE

\title{
ESPIRITUALIDADE, TERRITORIALIDADE: INTERFACES DAS REPRESENTAÇÕES CULTURAIS COLETIVAS INDÍGENAS
}

\section{SPIRITUALITY, TERRITORIALITY: INTERFACES OF INDIGENOUS COLLECTIVE CULTURAL REPRESENTATIONS}

\author{
Adnilson de Almeida Silva ${ }^{1}$
}

\begin{abstract}
RESUMO
O contexto apresentado no artigo procura discutir como as interfaces culturais em suas representações podem se relacionar diretamente com a espiritualidade na construção das territorialidades indígenas. Tais atributos constituem no esforço em compreender cientificamente como os indígenas realizam-se na construção do mundo e imprimem suas marcas representativas e simbólicas que permitem a acessibilidade da territorialidade pela mediação da espiritualidade, assim como a cultura - elo indissociável na apreensão da realidade de seu modo de vida e da compreensão de seu microcosmo. 0 universo conceitual dos "marcadores territoriais" constitui-se como uma parte das reflexões para o entendimento das relações indígenas na construção da cultura, da espiritualidade e da territorialidade, como possibilidade de entendimento das alteridades que se realizam na Amazônia, ainda que se apresentem com suas distinções e peculiaridades inerentes a cada etnia.
\end{abstract}

Palavras-chave: Amazônia; Espiritualidade; Indígenas; Representações culturais; Territorialidade.

1 Mestre pelo Programa de Pós-Graduação em Geografia pela Universidade Federal de Rondônia UNIR; Doutor pela Programa de Pós-Graduação em Geografia da Universidade Federal do Paraná UFPR; Professor do Departamento de Geografia e do Programa de Pós-Graduação Mestrado em Geografia da Universidade Federal de Rondônia - UNIR, Porto Velho, Rondônia, Brasil. adnilsonn@gmail.com 


\section{ABSTRACT}

The context presented in the article seeks to discuss how cultural interfaces in its representations can relate directly with the spirituality in the construction of indigenous territorialities. Such attributes, in assessment, are in an effort to understand scientifically as the natives are held with the building the world and print your representative and symbolic marks that allow accessibility of territoriality by the mediation of spirituality, as well as the culture - inseparable link in the apprehension of reality of their way of life and understanding of his microcosm. The conceptual universe of "territorial markers" constitutes as a part of the reflections to the understanding of indigenous relations in constructing culture, spirituality and territoriality, as possibility of understanding of otherness that take place in the Amazon, although presented with its awards and peculiarities of each ethnicity.

Keywords: Amazon; Spirituality; Indigenous; Cultural representations; Territoriality.

\section{Considerações iniciais}

O presente ensaio constitui-se num esforço de aprendizagem e resulta da convivência em trabalhos profissionais e acadêmicos com os indígenas da Amazônia, particularmente do Estado de Rondônia. As apreciações aqui expostas refletem nossa preocupação em demonstrar um pouco dessa nossa experiência, sendo inclusive resultado da tese "Territorialidades e identidade do coletivo Kawahib da Terra Indígena Uru-Eu-Wau-Wau em Rondônia: "Orevaki Are" (reencontro) dos "marcadores territoriais", em que apresentamos alguns excertos, além de outros pontos de vista adicionados à temática da espiritualidade e territorialidade indígena.

Temos a compreensão que ao se estudar a territorialidade de um coletivo indígena ou de um coletivo "tradicional", o nível das abordagens devem considerar os aspectos e fenômenos que compõem o corolário de sustentação à cultura. No âmago da discussão, a espiritualidade nos parece evidentemente ser um dos pilares que auxiliam na explicação e compreensão dos demais fenômenos e aspectos intrínsecos à identidade cultural.

Em tal construção identitária, as narrativas e seus desdobramentos repercutem na representação territorial e exigem do pesquisador um esforço, visto que a reflexão envolve um nível de complexidade - distinta da forma de 
pensar da sociedade envolvente - como condição de aproximação étnica, na qual compreendemos que se situa em duas esferas de análise interpretativa.

Em primeiro plano se trata de cultura com representação distinta da nossa - a da sociedade envolvente, além do que as variadas etnias são portadoras de formas próprias de representar-se em relação às demais. Assim, os símbolos representativos e os conteúdos simbólicos são dotados de características próprias de compartilhamento e representação de mundo - no qual a territorialidade e a espiritualidade se estruturam por meio de linguagens e concepções detentoras de estruturas simbólicas específicas.

Para efeito didático, a segunda esfera, mas não menos importante, está referenciada à própria vivência e experiência adquiridas pela ancestralidade, pela representação das territorialidades refletidas nos modos de vida. Essa é a trajetória teórico-empírica que fornece o embasamento de nossas reflexões sobre o sentido de entendimento, nas quais as narrativas indígenas estão imbricadas de espiritualidade e contribuem no estabelecimento das relações territoriais e do modo de se representar como coletivo e de se presentificar com os demais coletivos.

A importância das narrativas indígenas, como fenômeno intrínseco da espiritualidade, possibilita não tão-somente a compreensão sobre determinada etnia, mas como elemento estruturante que diz respeito a seus processos organizativos no espaço/território e no modo de vida, porque refletem a relação com o meio, compreendida como "microcosmo" (LEENHARDT, 1937; 1995; 1997, p.72 [1947]), cuja expressão ocorre em seu "espaço de ação" (CASSIRER, 1968, p.40-45 [1944]).

\section{A cosmogonia: um meio para compreender o microcosmo}

A cosmogonia refere-se a um processo sociocultural dos indígenas, e por meio de suas representações sociais e simbólicas usufruem das formas simbólicas, cujos elementos são solidificados como condições plausíveis ao desenvolvimento de mecanismos relacionados à defesa da integridade física, cultural e territorial, sendo efetivadas pela experiência no espaço de ação e pela ancestralidade de construção do microcosmo. 
Nessa direção, o símbolo se apresenta e é interligado ao mundo de significados, designa as representações e encontra-se como intercessor entre a matéria e o espírito e transcende o "divíduo" (STRATHERN, 2006) ${ }^{2}$ e a coisa, ao passo que o sinal é portador das artificialidades e convenções que integra o mundo material do ser e atua nas formas simbólicas para algo que ao ser qualificado torna-se (re)conhecido.

A análise interpretativa considera que os mais distintos modelos de culturas humanas estão diretamente relacionados aos diferentes períodos dos coletivos humanos condicionados à ideia de espiritualidade, porque essa é cosmogônica repleta de valores e rituais estabelecedores de relações, onde aproxima o divíduo se transcende por meio dos deveres, oferendas, rituais, sacrifícios e veneração, como condição de troca simbólica com os espíritos. Nesse particular, o conceito de "coletivo" descrito por Latour (2004, p.373) é no nosso entendimento o mais adequado, visto tratar-se de "um procedimento para coligar as associações de humanos e não-humanos", que se interliga ao conceito de "definição performativa de grupo" porque é "algo ininterruptamente constituído" (LATOUR, 2005, p.34,35).

A cosmogonia, como condição humana, nas mais distintas coletividades ao longo de suas trajetórias cosmogônica, geográfica e histórica não se desassocia das representações, formas simbólicas e presentificações, antes de tudo se constituem no fenômeno que origina "a organização de sua relação material e atinge a transcendência" (ALMEIDA SILVA, 2010, p.70). Logo, se consubstancia que o divíduo, como ser simbólico, está aprisionado por símbolos, signos, formas representativas que o possibilita apreender e compreender o microcosmo. É dessa relação com as representações que esse divíduo toma e torna-se referência a seu próprio microcosmo.

No contexto representativo da cosmogonia, os rituais são integrantes da espiritualidade e da territorialidade, sendo que as práticas e experiências proporcionam fenômenos de reflexão da própria existência, em razão da aplicabilidade de cumprimento de códigos que remetem à vontade e à

2 O contexto dado é que este conceito incorpora a noção de corpo e pessoa na sociedade melanésia, conforme afirma Strathern (2006, p.40-41): "as pessoas são frequentemente construídas como o lócus plural e compósito das relações que a produzem". 
mediação espiritual. Em tal sentido, esses rituais dos coletivos são caracterizados como "rituais de passagem", que como afirma Segalen (2002, p.11) "é sempre contemporâneo [...] o que existe, na realidade, é uma constante recomposição das formas simbólicas", cujo pensamento é aprofundado por Van Gennep (1978, p.123) que sua origem é "sempre na mesma ideia, a saber, a materialização da modificação da situação social".

Em realidade, os ritos também se inscrevem como parte peculiar das narrativas míticas, e essas por sua vez são contextos que retratam as experiências dos divíduos e das coletividades, em seu espaço de ação, como uma das formas de organizar o microcosmo, conforme expõe Almeida Silva (2010, p.70):

[...] O ato de caçar, pescar, plantar, colher, casar, ter filhos, morrer, sepultar os mortos, realizar lutas, conquistar territórios, entre outras ações resulta da conexão e da transcendência do espiritual com o material, o que exige o cumprimento de inúmeros ritos e rituais herdados, cosmogonicamente, pelos mitos dos heróis criadores do mundo e seus objetos - que também são seres portadores de espiritualidade [...].

A organização do microcosmo indígena reflete uma complexidade em que a materialidade é suplantada pela espiritualidade, sendo mais perceptível quando do acontecimento de rituais de passagens, e neles se manifestam com maior vigor o pertencimento identitário cultural e a linguagem portadoras de códigos e valores simbólicos peculiares à determinada cultura.

Outro aspecto representativo da espiritualidade reporta-se ao temor do desconhecido e à procura do seu Eu e do Outro Eu por meio das sensações e percepções que auxiliam nas incontáveis elucidações para compreender os fenômenos humanos e não-humanos, físicos e não-físicos. Dentre esses podemos situar os trovões, ventos, revoar dos pássaros, a presença dos espíritos, entre outros. Essas manifestações se materializam em ações e experiências obtidas nas representações e produzem sentido à territorialidade.

Esses fenômenos perceptíveis nas coletividades indígenas demonstram a afinidade com 0 meio e reciprocidade entre seres e não seres ${ }^{3}$. A

3 Compreendemos os não seres, como portadores de valores cosmogônicos representativos para determinado coletivo humano, cujo caráter de construção é entendido na subjetividade, intra e intersubjetividades, ou seja, como espíritos ou aquilo que não é palpável materialmente, ou melhor, etéreo, investidos de espiritualidade. Nele se incluem também as rochas, as montanhas, as estrelas, entre 
proximidade relacional do material com o imaterial, resultante da construção cosmogônica, permite-nos entender o que são "marcadores territoriais" e possibilita a compreensão das formas e representações simbólicas e presentificações como mediadoras do modo de vida (ALMEIDA SILVA, 2010).

Em nossa análise, os coletivos indígenas compreendem que todas as coisas existentes em seu microcosmo ultrapassam a materialidade e são interdependentes, ou seja, a supressão de qualquer elemento que compõe a cosmogonia provoca desequilíbrio espiritual e material, de modo a atingir indiscriminadamente a todos.

Essa representação holística de mundo possibilita a permanente reafirmação dos valores cosmogônicos, como um ciclo "eterno", simbolizado nas ritualidades, de forma que preserva espiritual e fisicamente os divíduos e a territorialidade, como apreensão ontológica do microcosmo.

A apreensão dos sentidos e os significados pelos coletivos corroboram com a criação e organização da cultura religiosa, social e intelectual de forma a expandir as representações de mundo por meio das mais distintas formas de se relacionar material e espiritualmente com seres e não seres, assim como o estabelecimento de rituais e doutrinas com valores que clarificam a compreensão das culturas.

\section{As representações como contexto da espiritualidade}

A análise reflexiva sobre as formas de representação e presentificação simbólicas dos coletivos possuem características que possibilitam a interpretação das culturas, nas quais a espiritualidade é um dos fenômenos que oferecem sustentáculo necessário à permanência cosmogônica, como condição da expressão do modo de vida.

Neste cabedal étnico-cultural, o nível de abstração, assim como a apreensão da realidade, encontra-se interligado a aspectos subjetivos, intersubjetivos e intrassubjetivos, o que implica diretamente na relação com o

outros, visto que são moradias de espíritos. Os não seres são incorporados simbólica e representativamente pelos humanos quando da "fabricação de corpos", sendo conhecidos e mantêm aproximação com os coletivos humanos, por exemplo, quando da criação do mundo relatada nas mais diversas narrativas míticas. 
microcosmo - em tal sentido, o meio em que vivem os coletivos, são fenômenos do próprio microcosmo construído pelas experiências e pelas dádivas consentidas pelos demiurgos, como condição de explicação e perpetuação desse microcosmo.

Como interpretação do microcosmo, para os coletivos indígenas, uma revoada de grilos ou de pássaros, ou ainda o florescimento de determinadas espécies florestais demonstram sinais com significados que são compreendidos coletivamente como prenúncio que algo está para acontecer com os seres e não seres. Os significados podem refletir na ordem pessoal ou coletiva sobre o microcosmo, e no seu arcabouço empírico - aqui compreendido como etnoconhecimento ou etno-saber como a relação de "mudanças climáticas, fartura e escassez de alimento, iminência de conflitos, surgimento de doenças, entre outras possibilidades, implicando na proteção social e territorial" (ALMEIDA SILVA, 2010, p.72).

Essa compreensão decorre do fenômeno cosmogônico de cada coletivo, sendo que o mesmo fato ou evento não possui o mesmo nível de apreensão de uma cultura em relação à outra, mesmo que entre elas apresentem algumas similitudes e evidencia a estrutura de linguagem simbólica, como fenômeno sensível, em razão dos sentidos obtidos pela percepção simbólica de mundo, em virtude de não existir um fenômeno sensível puro ao qual seja mensurado sentido posterior, mas sim fenômenos anteriormente idealizados com sentido, como símbolos (CASSIRER, 1994, p. 60 [1944]).

Em tal sentido, a natureza, como corporificação das relações dos divíduos e coletividades, é interpretada como mediadora simbólica com apreensão dos símbolos e representações obtidas sensorialmente pela experiência cosmogônica no espaço de ação e explicam os conteúdos fenomenológicos que ocorrem por meio da evocação aos espíritos e demiurgos, assim como de experiências sensoriais e visões psíquicas contidas nos sonhos e imaginações, as quais envolvem o uso de atributos êmicos dos seres e não seres que acessam a "fabricação de corpos".

O contexto conceitual de "fabricação de corpos", segundo Viveiros de Castro (1987, p.31), encontra-se relacionado ao "conjunto sistemático de 
intervenções sobre as substâncias que comunicam o corpo e o mundo: fluidos corporais, alimentos, eméticos, tabaco, óleos e tinturas vegetais", e implica diretamente na presentificação de seres e não seres, sendo essas representações simbólicas da espiritualidade e da conexão ancestral que conecta o anterior, a atualidade e o que virá posteriormente.

Entre os sentidos apropriados das expressões representativas simbólicas entre os coletivos indígenas e sociedades ancestrais, se manifestam nos mosaicos, mapas mentais ou cognitivos, ou ainda através de pinturas rupestres que representam atos de heroísmo, fartura de alimentos, realizações sexuais e espirituais, realizações de encontros tribais, trajetórias qualitativas de ocupação territorial, enfim a caracterização do modo de vida, como experiência do espaço de ação culminando com o que denominamos de "marcadores territoriais".

\section{A espiritualidade e os "marcadores territoriais": um caminhar possível}

A nossa compreensão é que os "marcadores territoriais" são componentes fenomenológicos construídos como representações simbólicas que transportam no seu âmago subjetividades e materialidades, de modo que contribuem essencialmente no entendimento sobre o desenvolvimento das atividades cotidianas, e, principalmente caracterizam o fortalecimento cosmogônico por meio do exercício da espiritualidade.

[...] os 'marcadores territoriais' são oriundos dos aspectos relacionados à espiritualidade, ao mito, à linguagem, à lembrança, à reverência aos mortos, à memória dos antepassados, à materialidade, às formas e às representações simbólicas que organizam o espaço de ação de determinado coletivo.

A partir dessas heranças, os indígenas cosmogonicamente constroem sua visão e interpretação de mundo como realidade objetiva por meio das formas, representações simbólicas e presentificações que operacionalizam seu modo de vida, dando o sentido das metáforas explicativas.

Compreendemos que o legado das formas, representações simbólicas e presentificações cosmogônicas oferecem a possibilidade de leitura geográfica dos 'marcadores territoriais', como lócus privilegiado de entender a construção da territorialidade e espacialidade indígena como uma sacralização que permite assegurar a continuidade e 
sobrevivência desses coletivos, a partir de sua leitura representativa e explicativa de mundo.

$\mathrm{Na}$ nossa avaliação como contribuição ao debate, consideramos que os 'marcadores territoriais' não podem ter uma rigidez monolítica, antes se intercambiam, ou seja, muito embora didaticamente possam ser classificados em determinada categoria, eles transcendem a própria categoria e relacionam-se com as demais e são expressivos portadores de uma morfologia identitária cultural, que possibilita entender as características simbólicas distintas entre os coletivos humanos [...] (ALMEIDA SILVA, 2010, p.120-121).

$\mathrm{Na}$ construção da territorialidade, as memórias dos coletivos indígenas estão associadas à espiritualidade, de modo que transportam a relação de ancestralidade com a materialidade vivida e experimentada na atualidade. Exemplo dessa relação ocorre com as antigas moradias ou malocascemitérios, que no caso dos Kawahib de Rondônia, retornam periodicamente a elas como forma de reencontrar com a história de vida do coletivo e de reencontrar-se com o próprio $E u$, dentro de uma introspectiva de espiritualidade e da perspectiva de continuidade em seu espaço de ação.

As antigas malocas, embora não se encontrem habitadas, são referências cosmogônicas porque nelas se realizam rituais espirituais e sociais, inclusive como referenciais territoriais, porque despertam percepções e sentimentos de reverência, de histórico de vida do coletivo, que se ampliam e multiplicam fenomenologicamente como imprescindíveis à identidade e ao pertencimento étnico.

[...] As malocas, em nossa análise, são antigos referenciais de espiritualidade e territorialidade, que possibilitam o 'Orevaki are' (reencontro) não somente com as formas e presentificações nos túmulos de seus antepassados, mas principalmente com 0 processo de permanência da organização sociocosmogônico e territorial. Não se refere apenas a um 'Orevaki are', em que se celebram a vida, nem a ocasionalidade, transcende ao aspecto material, verificando-se o congraçamento social e a expressão de sua espiritualidade, em que se manifestam ritos e rituais, arte e o agradecimento pela trajetória percorrida com 0 auxílio dos espíritos [...] (ALMEIDA SILVA, 2010, p.74-75).

A espiritualidade que os Kawahib estabelecem como reverência aos parentes falecidos - considerados como espíritos protetores da cultura e do 
território - assemelha-se à percepção descrita por Mumford (1991, p.16 [1961]) ao considerar as primeiras formas de organização humana na Terra:

[...] o respeito do homem antigo pelos mortos [...] teve um papel maior ainda que as necessidades de ordem mais prática, ao fazer que procurasse um local fixo, um ponto fixo. Os mortos foram os primeiros a ter uma morada permanente: uma caverna, uma cova assinalada por um monte de pedras, um túmulo coletivo. Constituíam marcos aos quais provavelmente retornavam os vivos a intervalos, a fim de comungar com os espíritos ancestrais [...].

Nesse caso, evidencia se que a espiritualidade se perpetra na origem de inúmeros coletivos e suas culturas, sendo que o sagrado ultrapassa as "fronteiras do conhecido" pelos humanos, e no caso dos Kawahib, as malocas são lugares que fazem interface do mundo material e acessam o "espaço transcendente".

A concepção do microcosmo é anterior à materialidade, em razão da gênese dos humanos, dos seres e não seres se caracterizarem como construção da vontade dos demiurgos - heróis míticos criadores, que através de suas genialidades, criatividades, inventividades e divindades conceberam a existência humana, a territorialidade e o microcosmo.

Desse modo, o conjunto cosmogônico é celebrado, como perpetuação do processo fenomenológico e se circunscreve na forte relação introspectiva, na qual os rituais, as reverências e os valores construídos possam ser mantidos, porque intuitivo e simbolicamente, representa a continuidade do coletivo na realização do espaço de ação e das respectivas representações indígenas.

Essas representações são a base para compreender a territorialidade e os "marcadores territoriais" situados como uma rede de ações no espaço, cujo caráter é concebido através da socialização como fenômeno de construção e reconstrução dos valores coletivos, em que a espiritualidade é o principal fenômeno dessa constituição estruturante.

Essa lógica de concepção envolve a vida coletiva e sua constituição com fundamento cosmogônico, em que os mitos em suas formas e representações simbólicas se presentificam em vinculações integradoras entre seres e não seres, consubstanciando a etnogeografia ou geografia indígena. A profusão 
dos fenômenos desses estatutos é o que caracteriza a cultura, sendo essa a expressão das morfologias simbólicas existentes nas mais distintas coletividades.

É o caráter de apreensão das representações simbólicas, nas quais a espiritualidade se apresenta como um dos fenômenos intrínsecos de cada coletivo, conjuntamente com o estabelecimento relacional com o ambiente através das experiências no espaço de ação, que as culturas possuem suas similitudes e distinções e propiciam a afirmação do pertencimento como coletivo, se constituindo como etnias, como representação do microcosmo.

Essa maneira complexa de pensar o microcosmo a partir da vivência e da percepção com o ambiente oferece a perspectiva que a geografia indígena imbricada de formas e representações simbólicas não aborda somente os aspectos ligados ao cotidiano, mas, nomeadamente, é uma expressão da ancestralidade cominada pela cosmogonia logo, espiritualizada - sendo um dos caminhos possíveis para se compreender os divíduos e coletividades em suas lógicas de apreensão de microcosmo.

Em tal sentido, a lógica das formas e representações simbólicas e presentificações, na qual os seres e não seres se encontram aprisionados pela cosmogonia, infere-se na relação do processo genealógico, como dádiva herdada dos demiurgos, tendo o sentido de "marcadores territoriais".

Essa concepção é traduzida territorialmente, enquanto a sua essência é espiritual, ou seja, as nomenclaturas geográficas como rios, montes, serras, montanhas e outros componentes da paisagem recebem a toponímia em conformidade à designação formadora das metades exogâmicas ${ }^{4}$, como se verifica entre os Kawahib ${ }^{5}$ de Rondônia.

4 Essas metades possuem uma configuração que perpassa os aspectos materiais, porque é constituída por mediação cosmogônica determinada pelos demiurgos de um coletivo, culminando nas relações sociais, de parentesco e território, em que o casamento fortalece essas relações no interior do coletivo, ocorrendo com a intersecção entre duas famílias, o chamado casamento cruzado entre primos. 0 compartilhamento do microcosmo em metades é uma coesão que permite a organização coletiva, social e territorial como experiências no espaço de ação.

5 As metades exogâmicas dos Kawahib, conforme Kracke (1984) e Peggion (2005) são constituídas pelos: a) Kanindewa (Arara), criados por Yvaga'nga, representam a sobrenatureza, ou seja, as coisas que estão no céu; b) Mutum Nhangwera (Mutum), concebidos por Mbahira'nga, representa a cultura e estão relacionadas às coisas terrestres; c) Gwyrai'gwara é criação de Anhang, está relacionado às questões da natureza e seus fenômenos - refere-se ainda a casamentos não cruzados e a casamentos com outras etnias, inclusive com não indígenas. O arranjo cosmogônico exogâmico possibilita um microcosmo em 
A complexidade Kawahib, que se apresenta nesse processo, é estendida em outros fenômenos de espiritualidade e territorialidade, como exemplo o rio é nominado pela cor, extensão, volume, largura e profundidade, em que cada trajeto e distinção de seu curso, conforme o quesito a ele atribuído está associado a uma das metades exogâmicas, em decorrência do estabelecimento cosmogônico atribuído aos seres e não seres.

Todavia, isso não se constitui em empecilho para que a outra metade possa usufruí-la para garantir a sobrevivência. A nominação dos montes, serras, cavernas, plantas, animais, demais seres e não seres, como "marcador territorial", configura-se no acesso possível - mas não o único para compreendermos o microcosmo dos Kawahib, sendo também um dos indicadores da espiritualidade e territorialidade.

[...] É importante observar que a construção da espacialidade indígena e o modo de vida como experimentam o espaço, num primeiro momento se apresenta relativamente parecido como extremamente banal para nós, entretanto é preciso mencionar que essa concepção tem seus equívocos, isto porque somente com a vivência e a compreensão de certos fenômenos é que se pode revelar um intrincado conjunto que perpassa o caráter visual [...] (ALMEIDA SILVA, 2010, p.76).

Outro aspecto que julgamos importante na análise sobre a espiritualidade e territorialidade indígena como "marcador territorial" pode ser constatada com a confecção de armas utilizadas na caça, na pesca e para o combate com possíveis inimigos.

Constatamos entre os Kawahib de Rondônia - Jupaú ou Pindobatywudjara-Gã e Amondawa - que uma flecha feita com a mesma matéria-espírito aparentemente igual para a sociedade envolvente, essa possui qualidades e sutis diferenças em sua forma de confecção, devido a sua representação simbólica para os divíduos em suas metades exogâmicas.

Assim, sua concepção está vinculada a uma dádiva cosmogônica, alocando-se a intencionalidade e espiritualidade de quem constrói, ou seja, ocorre por inspiração e conhecimento oriundo de um demiurgo. O que queremos afirmar é que a forma distinta da concepção de objetos e utilização,

que árvores, peixes, animais, montanhas, rios, entre outros, seja de uma ou de outra metade, e consubstancia o que chamamos de "marcadores territoriais". 
seja uma maloca ou uma flecha, não ocorre com o sentido de encerrar em-simesmo, porque são portadores de valores que englobam espiritualidade, territorialidade e experiências acopladas aos fenômenos cosmogônicos e ancestrais.

Logo, a geografia representativa por intermédio dos "marcadores territoriais" se reveste de valores qualitativos reafirmando as vivências e experiências realizadas no espaço de ação como possibilidade de incluir e perceber o arranjo geográfico dos indígenas, na perspectiva de compreensão da "totalidade do ser" e da "orientação cósmica" (LÓPEZ, 2006).

\section{O realizar das representações Kawahib na espiritualidade e territorialidade}

As experiências vividas no espaço de ação demonstram a pertinência quanto às temporalidades e aos acontecimentos significativos para o coletivo $e$ contribuem na organização dos "marcadores territoriais", como condição de construção do geográfico, inserindo-se nelas as formas e representações simbólicas e presentificações de concepção espacial.

As heterogeneidades de apreensão e interpretação do microcosmo se materializam com o pertencimento cultural repleto de valores cosmogônicos, em que a territorialidade está diretamente interconectada à espiritualidade, e essa atua como mecanismo de defesa física do território e da perpetuação cosmogônica. Logo, as representações, formas e presentificações sem sombra de dúvida, transportam no espaço, a proeminência das experiências humanas como partícipe do modo de vida.

Portanto, a constituição dos objetos e sua utilização são realizadas através de ritualísticas e não podem ser consideradas como meros acontecimentos ou simples desejos dos humanos, isto porque se encontra sob o auspício cosmogônico, o qual se encontra os sinais e signos da natureza e os espíritos e "donos" das florestas, rios, montanhas e animais.

Essa coerência do pensar e agir indígena norteia a vida em suas ações de cotidianidade e ancestralidade, de forma que o coletivo é um detentor de 
concepções que auxiliam a realização do espaço de ação, como motivador do realizar-se no microcosmo, determinando o modo de vida.

O modo como concebem e vivenciam o microcosmo apresentam outros ordenamentos de "marcadores territoriais" pela utilização de suas tecnologias e etnoconhecimentos, sendo indicadores culturais e espirituais que garantem a sobrevivência do coletivo, entre elas a etnomedicina e a etnobotânica, com as quais extraem espíritos êmicos necessários ao acesso à transcendência espiritual, ao tratamento de doenças, à captura de animais e peixes, à defesa do território e à formação de alianças com outras etnias.

Essas características da geografia Kawahib são um importante instrumento de análise interpretativa e permitem alcançar a realidade impenetrável materialmente, entretanto, intrinsecamente encontram-se no divíduo e no coletivo que as vivencia por intercessão das experiências cosmogônicas.

No contexto da complexidade indígena, o etnoconhecimento propicia a realização de seu microcosmo com exercício das práticas elaboradas no espaço de ação, constituindo a rede de organização coletiva, em que se revela a espiritualidade e seu conjunto de valores que qualificam a representação e expressão de sua visão de mundo.

Deste modo, a geografia indígena, com sua forma simbólica se concretiza como exercício coletivo, ciente de que o divíduo transporta a ideia de vários outros Eus, configurando-se como multidão que transporta em seu interior infinitos seres e não seres, cujo sentido é representativo e presentificado coletivo e holisticamente.

O contexto da afirmação Kawahib é constatado com maior ênfase às representações relativas ao Nós (Are) como o próprio coletivo e ao Nós (Ore) com aqueles que pertencem a outras etnias. Essa concepção qualifica-se como fenômeno decorrente da consciência de concepção, apreensão e visão de microcosmos distintos em suas mais variadas representações simbólicas e implica, por conseguinte, nas experiências no espaço de ação, configurando o que menciona Cassirer (1968, p.178 [1944]), como sendo aquilo que "não pode 
ser outra coisa senão a unidade formal da consciência na síntese múltipla de nossas representações".

Essa consciência Kawahib indica a relação espiritual e territorial de instituição de conhecimento plural que reforça o caráter de pertença identitária e enraizamento no espaço, como representação simbólica do microcosmo em um processo de apropriação e internalização, cujas dimensões são simbólicas, e possibilitam a compreensão dos divíduos e coletivos em suas múltiplas relações internas e externas no território e configura-se como cultura.

Tal condição representativa do coletivo Kawahib é plena de vivências interpretadas e vividas no território, de modo a orientar a vida e estabelecer as relações internas de construção e afirmação de pertencimento coletivo e externamente como qualidade de se apresentar perante as demais sociedades.

Por essa qualidade, as representações simbólicas detentoras de valores cosmogônicos e socioculturais vinculam-se aos aspectos geográficos, marcadas na simbiose dialética entre o divíduo, o coletivo e a coisa simbólica, tendo como ponto de partida a apreensão do significado representativo da linguagem do coletivo.

Em tal análise, os símbolos, como conteúdos da representação, são organizados como possibilidade de acessibilidade ao contato social com outros seres e não seres, em que a linguagem possui a qualidade de ajustar as afinidades do próprio microcosmo do coletivo.

Assim, a representação do coletivo é originária da imagem simbólica estabelecida pela herança cosmogônica - na qual a espiritualidade, a territorialidade e a cultura são componentes - e pela relação de apreensão em relação ao outro.

Essa conceituação basilar remete ao argumento de Reale (1997, p.25) de que "o indivíduo é um sócio entre os demais e partícipe consciente ou não do complexo de imagens, símbolos, fórmulas, leis, instituições, etc.”. A condição de organização do microcosmo implica diretamente na compreensão em que o divíduo não se encontra sozinho no mundo, e sim se depara com entrelaçado de realidades concentradas e abstratas marcadas pelas mais 
variadas experiências do espaço de ação, o que culmina com o exercício do modo de vida coletivo.

Logo, entendemos que o contexto representativo da etnogeografia está repleto de experiências cosmogônicas - espiritualidades, ancestralidades, territorialidades e historicidades - onde o vivido e experimentado pelo coletivo indígena se presentifica como condição de ordem infinita (tempo e espaço) e possibilita a esse coletivo em qualquer circunstância permanecer no seu núcleo de origem. Esta é a lógica de representação dos Kawahib como "Orevaki are" (reencontro), dando o sentido de reafirmação de pertencimento coletivo identitário.

Com essa abordagem, a representação no conjunto cosmogônico explica elementos intrínsecos e extrínsecos dotados de qualidade na formação da territorialidade, da identidade, da espiritualidade e da cultura do coletivo Kawahib, que, todavia, exige um empenho de análise interdisciplinar, considerando que os fenômenos cosmogônicos não são estanques e transcendem a aparência e a materialidade das coisas postas no microcosmo.

Essa concepção do microcosmo, em face à sua complexidade, é caracterizada como um fenômeno estruturante e não é adquirida ou compreendida em sua totalidade, mas se ancorada numa intrincada relação mais densa em que a espiritualidade e a experiência se realizam como condição para a edificação da territorialidade, como experiência do coletivo no espaço de ação. Assim, a cosmogonia e seus valores são anteriores ao surgimento do divíduo, de modo que marca a territorialidade de um coletivo, como condição da existência deste mesmo divíduo.

Sob essa ótica, a cosmogonia é plena de conteúdo simbólico na construção do espaço-territorial com suas formas, representações, mitos, signos e outros elementos indispensáveis que constituem a etnogeografia, cujo caráter se fundamenta com a espiritualidade.

O contexto etnogeográfico, como se vê, possui nuances que possibilitam análise de temas, cuja relevância não é adquirida e compreendida com o reducionismo, antes necessita uma imersão em que as percepções, sensações - como inatingíveis materialmente, mas que através das representações 
simbólicas ganham dimensões plausíveis de explicações, dado seu caráter subjetivo.

Em face à representação espacial etnogeográfica, o divíduo fabrica seu corpo holístico nessas subjetividades e pelas necessidades existenciais, cuja percepção e sentido encontram-se inseridos nos signos, códigos e representações simbólicas, sendo que esse divíduo transporta consigo o etnoconhecimento e as abstrações espaciais de microcosmo situadas na óptica de suas vivências e experiências adquiridas com a cosmogonia e o espaço de ação.

Destarte, o indígena tem como âncora as formas, representações simbólicas e experiências cosmogônicas verticais - espiritualidade e fenômenos míticos - e horizontais como trabalho, liderança, ideologia, entre outras, que adjudicam seu pertencimento coletivo. Essa concepção remete a seus comportamentos como díviduo e como coletivo capaz de qualificar o território e a própria identidade, dando uma configuração que o distingue culturalmente em relação aos demais coletivos.

O apresentar e representar são consolidados subjetivamente, tendo como pressuposto a pregnância da espiritualidade, verdades, desideratos, fobias e outras manifestações intrínsecas aos divíduos e aos coletivos construídas no arcabouço de suas memórias cosmogônicas e ancestrais.

Esse entender o microcosmo permite-nos refletir que as representações simbólicas de territorialidade são distintas entre os diversos coletivos em razão do que os demiurgos desempenham frente a essas coletividades, adquirindo 0 sentido de argumentação observada por Gallois (2004, p.40) que "o território não é uma noção que remete apenas ao espaço físico mas sobretudo a concepções cosmológicas".

O sentido mais amplo da noção da territorialidade é sua conexão com a espiritualidade, na capacidade perceptiva de enxergar além das aparências e dos objetos que são colocados sobre a terra, isto porque o todo se constitui de sacralidade e nela está clara a nossa de lugares tangíveis e intangíveis, de espaços que podem ou não ser acessados. Esse nível de compreensibilidade é notadamente presentificado no discurso dos divíduos mais experientes do 
coletivo, enquanto os mais jovens compreendem a territorialidade a partir dos limites fixados pela sociedade envolvente.

Em relação a essa questão, é necessário explicitar que o nível de relação cosmogônica se distingue de coletivo para coletivo, em razão da apreensão das representações simbólicas e das experiências no espaço de ação, de modo que simbólica e categoricamente consubstancia a percepção de microcosmo. Isso implica dizer que um coletivo está aprisionado a uma série de valores, principalmente espirituais, que não são entendidos na mesma dimensão do que outro coletivo.

Neste particular, a revelação do simbolismo representativo, em maior ou menor aproximação de espiritualidade de cada coletivo, assim como o número de "guias espirituais", não pode ser mensurada por meio de uma percepção estereotipada, no sentido de valorizar uma cultura ou negar outra em sua trajetória de espiritual ${ }^{6}$ e de experiência transcendental.

[...] A leitura realizada pela sociedade envolvente sobre o mundo espiritual dos indígenas e com reflexo na territorialidade não pode ser compreendida em sua totalidade, porque implica em outros valores e conhecimentos que não podem ser revelados de forma imediata a nós [...] (ALMEIDA SILVA, 2010, p.225-226).

Essa afirmação do autor conduz a reflexão das especificidades essenciais que a cultura produz e representa simbolicamente o papel da territorialidade quão intensamente plena de processos estruturantes em cada coletivo, interagindo com o microcosmo e apoiado na cosmogonia peculiar, cujo aspecto pertinente é o próprio pertencimento coletivo.

A peculiaridade do pertencimento coletivo, a qual se justifica a existência do microcosmo configura-se no que Schechner (1988, p.32-33) categorizou como totalidade, ou seja, o processo de nascimento, crescimento, objetividade e experiência transcendental, cujo atributo é baseado na oralidade, logo, marcando as distinções culturais de cada coletivo e ainda da sociedade envolvente. Essa operacionalidade se realiza pelo fenômeno da apropriação

6 Entendemos, como de salutar importância sobre a espiritualidade indígena, o trabalho de Mindlin (2009, p.195-207) que considera os ritos e ritualidades como fenômenos cosmogônicos da espiritualidade, de modo que sua complexidade representa a própria complexidade do microcosmo em suas múltiplas relações e dimensões, considerando essenciais ao modo de vida. 
cosmogônica com seus símbolos, representações, manifestações e rituais espirituais, que coloca o divíduo no centro da transcendentalidade.

Essa qualidade do divíduo se transcender espiritualmente insere-o como partícipe na relação entre seres e não seres, de modo que pode se "transmutar" em outro ser ou não ser. Neste sentido, as narrativas míticas constituem-se como padrões que auxiliam a nossa análise, isto porque 0 homem é peixe, é planta, é rio e floresta, em razão do universo relacional intrínseco em que a existência de tudo é integrante do todo e essa condição implica a representação do microcosmo espiritualizado.

Ao analisarmos o contexto descrito por Schechner (1988), sobre a totalidade processo da identidade cosmogônica, amplia-se a compreensão do espaço de ação e da territorialidade manifestadas pelos "marcadores territoriais", em que os distintos coletivos qualificam o espaço ou território em conformidade com a representação simbólica do microcosmo.

Em tal tessitura, a cosmogonia é mediadora na relação entre os diversos coletivos de uma região (SCHECHNER, 1988), e atua como promotora das trocas objetivas, intrassubjetivas, intersubjetivas, simbólicas e de rearranjos de subjetividades, de modo a possibilitar espaços de aproximação, de experiências, de mudanças e permanências culturais.

Em nossa análise, parece-nos evidente que a mediação cosmogônica dos Kawahib de Rondônia subjetiva e concretamente é realizada em espaços especiais revestidos de sacralidade e espiritualidade, como é o caso de antigas malocas-cemitérios.

[...] a maloca apresenta-se como uma representação importante e indispensável para a cultura, vivência e a própria territorialidade, refletindo diretamente no modo de vida do povo e no estabelecimento de suas relações internas e externas. A compreensão do significado de uma maloca é muito mais do que um atributo físico, é também psíquico e espiritual, é a própria alma e história que está presente em seus gestos e ações. [...] a maloca no passado tinha múltiplas funções que auxiliam na explicação do entendimento das representações, sendo a primeira para 0 atendimento como moradia e sustentáculo as atividades agrícolas tradicionais, a segunda função como 'marcador de território' oferecendo a defesa do grupo, e por último, mas não menos importante era servir como cemitério [...] (ALMEIDA SILVA \& SILVA, 2007, p.02). 
A maloca como representação simbólica é plena de espiritualidade, sendo percebida e sentida atualmente como espaço de acessibilidade à reflexão do divíduo e do coletivo, cujo significado simbólico remete à trajetória cosmogônica e das experiências no espaço de ação. Sua função cosmogônica como "marcador territorial", é operar como moradia de seres e não seres (espíritos); para o exercício da memória coletiva, com 0 atributo de sociabilidade que se realizam com os moronguetá (diálogos indígenas); para o entendimento da territorialidade e da defesa física do território e da cultura; e, sobretudo, para o exercício das experiências espirituais.

[...] No processo de construção, a territorialidade é compreendida a partir das relações de objetividade material e da subjetividade, medidas nas percepções humanas, como elementos formadores de identidades. Como criações humanas, o território e o tempo estão circunscritos à dependência da valoração sobre o que atribuímos aos objetos construídos pela ação humana, logo se diferencia em relação às mais variadas sociedades, através de sua visão de mundo, cultura e modo de vida, em suas diferentes escalas de poder $\mathrm{e}$ de representatividade [...] (ALMEIDA SILVA; GIL FILHO \& SILVA, 2008, p.36-37).

No contexto descrito pelos autores, é evidenciado que o caminhar dos coletivos se fundamenta na cosmogonia, sendo que os mitos são componentes fenomenológicos dessa construção e envolvem as relações e manifestações do espírito humano, entre elas as ansiedades, as confiabilidades, os temores e as incertezas e outras manifestações percebidas e sentidas pelos divíduos e coletivos. Como fenômeno, as representações são possibilidades que se colocam para explicação do microcosmo e de todas as coisas que não são plenamente compreendidas racionalmente pelos divíduos, e somente podem ser concebidas e mediadas pelas representações simbólicas.

Por seu turno, essas representações não são conjecturas de desvarios e devaneios, porque se entende que estão relacionadas a fatos e experiências que consubstanciam o espaço de ação cosmogônico. Assim, ao se fazer referências às representações, em realidade 0 divíduo encontra-se manifestando o seu próprio modo de vida e o realizar coletivo como pertencimento identitário. 


\section{Espiritualidade, mitologias e "marcadores territoriais": algumas representações cosmogônicas dos Kawahib}

A mitologia se inscreve na cosmogonia Kawahib, como um dos mais importantes fenômenos de representação simbólica, isto devido à existência de conexões relacionadas aos mistérios, à convivência humana e aos processos de apreensão e historicidade eficazes na elaboração do espaço de ação e da legitimação dos atos humanos inclusos na espiritualidade.

As narrativas míticas do coletivo Kawahib, enquanto fenômenos, possibilitam a edificação estruturante de organização do modo de vida e é imprescindível ao empoderamento no interior do coletivo, pelo fato de materializar a historicidade e geograficidade, por meio das multiformas simbólicas, ao tempo em que com a espiritualidade, ritualidades, percepções e sensibilidades marcam não apenas a materialidade, mas, principalmente, 0 realizar da cosmogonia.

De tal modo, as narrativas míticas permitem acessar a cosmogonia e proporcionam a formação física, psíquica e espiritual do coletivo, sendo ainda o contributo essencial fundante da identidade cultural. É do caráter mítico impregnado no divíduo e no coletivo que se expressa a identidade cultural e pertencimento e resulta na "fabricação de corpos" plenos de seres e não seres, ou, em outras palavras, podemos afirmar que se trata da espiritualidade intrínseca em cada cultura.

Nessa análise, entendemos o mito como mediador conectivo da consolidação social estruturante do modo de vida, cuja concepção exprime fenomenologicamente as explicações e as experiências do espaço de ação, visto que o mito é a própria representação simbólica do microcosmo de um coletivo.

Destarte, o mito para os coletivos indígenas possui o sentido de fortalecimento, de organização, de orientação para 0 exercício das experiências no espaço de ação, porque ao ser internalizado e qualificado produz subjetividades, formas, representações, simbolismos e presentificações que propiciam pertencimento, territorialidade e imprime qualitativamente marcas e valores do microcosmo, cuja compreensão é cosmogônica. 
Em sua regulação, o mito, como metáfora simbólica indica os percursos da internalização moral cosmogônica, em que possibilita a orientação, a apreensão de ensinamentos e exemplificações utilizadas a sociabilização do coletivo, de modo a prover o imaginário e o espírito. Com isso, ao divíduo é consentida a decodificação e aplicação do conhecimento advindo das narrativas míticas como imprescindível a operacionalização do espaço de ação e do modo de vida no interior das coletividades.

A relação do mito, como metáfora explicativa, é constituída de histórias com cenários de interação espiritual que ao se decodificar em formas e representações, com a característica conectiva de entrelaçar humanos, seres e não seres, e, pelas qualidades inerentes a esta, tem como expressão coletiva o imaginário com autoridade para estabelecer o pertencimento e o enraizamento étnico-cultural dos divíduos e coletivos.

Essa afeição da organização mítica cosmogônica é a competente ordem de regulação do microcosmo que atua no imaginário, na representação, na espiritualidade e na materialidade apreendidas pelos indígenas como condição de existência do divíduo, do coletivo, da identidade, das relações de sociabilidade, das relações com os seres e não seres, e que se configura como permanência ou pregnância cosmogônica indispensável à identidade e ao pertencimento identitário.

No microcosmo cosmogônico Kawahib, a espiritualidade habita 0 invisível, as materialidades, o surgimento das coisas, das expressões e das representações de modo que ordena e dá feição e qualidade ao espaço, em que os "marcadores territoriais" são integrantes inerentes do microcosmo, como condição ao exercício das experiências no espaço de ação.

Neste aspecto, os "marcadores territoriais" íntegros de cosmogonia, de representações e expressões simbólicas são dotados de valores dos mitos, com isso "pode nos auxiliar na formulação de problemas relativos à organização social" (MATTA, 1973, p.19). Logo, se compreende que pelos mitos se elaboram a territorialidade como afirmação da espiritualidade, de maneira que se manifestam as experiências e vivências no espaço de ação - e este espaço é caracterizado como o adequado microcosmo do coletivo. 
$\mathrm{Na}$ relação entre espiritualidade e mito, o microcosmo é habitado por espíritos que longe, de serem maniqueístas, distribuem e lideram valores apreendidos pelo coletivo, de forma que propiciam a elaboração do modo de vida. Assim, é possível afirmarmos, no nosso entender, que os mitos descritos nas narrativas indígenas, na realidade, demonstram a apreensão do microcosmo, sendo que a denominação de bem ou mal - na nossa visão de sociedade envolvente - possui outras dimensões qualitativas para os indígenas.

Verificamos, entretanto, nas coletividades indígenas que as qualidades cosmogônicas produzem territorialidades afetivas ou restritivas, em virtude dos significados de suas representações, sendo que o mito atua como contribuinte no modo de vida, ao tempo que propicia o exercício das práticas ritualísticas de espiritualidade na fabricação dos corpos dos divíduos e dos coletivos, auferindo identidade e pertencimento. Aqui fica evidente a ação dos demiurgos - espíritos míticos criadores - como organizadores da criação e do modo de vida dos coletivos.

Uma dos espíritos temidos pelos Kawahib é Anhangá em razão das ações que pratica - ele está ligado às manifestações da natureza. $\mathrm{Na}$ descrição de Hurley (1934, p.117): Anhangá é o "filho mais velho de Jurupary, que é o irmão mais moço de Tupan [...] vive na terra a seduzir as almas para o seu reino encantado, no centro da Terra [...] protege e persegue os guerreiros em combate e de sua sympathia depende a Victoria [...]".

No imaginário Kawahib, o espírito de Anhangá é afastado através de evocações de outros espíritos e pela claridade, em razão desse espírito atuar na escuridão. O espírito de Anhangá é temido por se materializar em qualquer outro ser e não ser, de modo que realiza eventos e ações que oferecem algum dano ao divíduo e a coletividade.

Em análise às narrativas míticas sobre Anhangá descritas em nossa tese, constatamos que sua ação surge quando da "violação" dos valores cosmogônicos e das fragilidades espirituais do divíduo ou do coletivo. Como ilustração da ação desse espírito, Arimã-Ga da Aldeia Djaí em abril de 2007 apresenta a seguinte narrativa: 
[...] Quando saiu da maloca, a mulher grávida morreu, mas a filha que ela tinha na barriga não morreu. $O$ marido ficou sozinho, ele fez a flecha, depois pegou a menina para proteger e aí apareceu Anhangá. Anhangá deitou-se com a menina engravidando-a, depois a levou para pintar com jenipapo, lá no jenipapeiro. Aí ele fez a pintura, então disse: 'vamos pintar nosso filho'. Jogou o jenipapo fora e depois Anhangá desapareceu. Quando foi embora, ele virou capim, depois virou abelha, depois jaguar (onça), e saí por aí fazendo suas travessuras e maldades. Gosta de assustar as crianças. Quando morre alguém, tem que chorar muito e rezar coisas de índio senão Anhangá volta para levar embora os outros

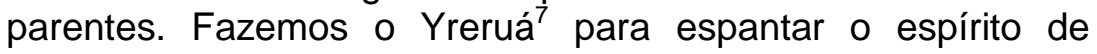
Anhangá [...].

Assim, o contexto da simbologia descrita na narrativa mítica aponta para formas, representações e presentificações, em que o sentido consiste na espiritualidade e identidade, com destaque para as experiências e relações entre seres e não seres, ao tempo que se reafirma os valores cosmogônicos do coletivo.

Nesses atributos, os "marcadores territoriais" são inscritos na subjetividade e no simbólico e são capazes de transcender o espaço de ação do coletivo, visto que são investidos de espiritualidade. Portanto, os "marcadores territoriais" ao se tornar representações, possibilitam a permanência dos fenômenos cosmogônicos e contribuem na organização do microcosmo e em seus desdobramentos, como modo de vida, identidade, pertencimento e espaço de ação.

O conteúdo dos "marcadores territoriais" enfatiza que as representações e formas simbólicas são clarificadas por meio das metades exogâmicas na organização social dos Kawahib, e ocorre também em outros coletivos humanos, sua caracterização é a territorialidade e a identidade, com origem a partir da espiritualidade centrada em demiurgos ou heróis míticos fundadores.

Neste contexto, uma das representações cosmogônicas e sociais de organização do microcosmo Kawahib é obra da engenhosidade e genialidade de Baíra (NUNES PEREIRA, 2007 [1944]) ou Bahira (PAIVA, 2005).

7 O Yreruá é um ritual indígena Kawahib realizado por meio de orações, cantos e danças, cujos objetivos são o de expulsar os espíritos inimigos, fortalecer espiritualmente o coletivo e o território e celebrar a vitória sobre os inimigos do coletivo. 
Na narrativa descrita por Nunes Pereira, Baíra criou o Sol (homem) da raiz da paxiúba Socratea exorrhiza e a Lua (mulher) da raiz do apuí, resguardando-lhe os respectivos papéis de representatividade e presentificação social e de construção da coletividade, que se realizam também na cotidianidade. Logo, essas representações são detentoras de espiritualidade, em razão do regenerar-se constantemente, do ressurgimento a cada noite e manhã, transporta consigo objetiva e subjetiva as naturezas masculina e feminina, e que constitui o ritual da vida.

Em Paiva, a narrativa percorre trajetórias relacionadas à territorialidade, cuja simbologia se realiza com adoção de seres e não seres êmicos espiritualizados que são pintados em suas respectivas metades para não se misturarem, porém o compartilhamento do microcosmo é para todos os divíduos do Coletivo.

A territorialidade Kawahib, com seus "marcadores territoriais", com isso possui peculiaridades que configuram as identidades das metades, cujo conteúdo de representação é materialidade e imaterial em suas múltiplas dimensões em virtude do processo estruturante e da experiência do espaço de ação, que resultam no modo de vida permeado de espiritualidades.

\section{Reflexões finais}

A apreensão reflexiva sobre a qual debruçamo-nos neste ensaio, não se encerra na presente discussão, até mesmo porque a forma de apropriação simbólica é algo que se encontra inerente a cada divíduo e em cada coletivo, isto é, sua realização está relacionada à subjetividade com que compreende o microcosmo.

Isto é, cada coletivo possui sua própria forma de representação e significação simbólica. Logo determinado objeto não possui o mesmo grau de relevância quando comparado entre um e outro coletivo, porque o processo estruturante é distinto, as dádivas dos demiurgos são distintas, as espiritualidades e os momentos de apreensão ocorrem com características peculiares com peso simbólico realizado de maneira que só é entendida por 
aquele coletivo. Daí decorre toda a dificuldade em se fazer a análise dos microcosmos.

Essa qualidade que ocorre no interior dos coletivos, contudo, permitenos refletir que a construção da identidade encontra-se associada à territorialidade e aos fenômenos da espiritualidade cosmogônica e às experiências no espaço de ação como possibilidades de construção da existência do divíduo, do coletivo e do microcosmo indígena.

A compreensão da territorialidade, da identidade e da espiritualidade é possível mediante o estudo das representações simbólicas, dos símbolos e dos signos que implicam na constituição do modo de vida e dos "marcadores territoriais" e não podem ser vistas apartadas da cosmogonia de cada coletivo.

Em nossa avaliação, os "marcadores territoriais", como componentes intrínsecos da espiritualidade e da cosmogonia, estão relacionados aos seres, não seres, alimentos, bebidas, pinturas e expressões corporais, ritos e rituais indispensáveis na "fabricação de corpos", cujo conteúdo simbólico-espiritual possui qualificação distinta entre os coletivos.

Essa condição peculiar de representações acarreta na definição de microcosmo, inclusive sobre o que se pode beber ou comer, ou ainda sobre em quais períodos são permitidos caçar, pescar, construir malocas e roças, realizar rituais, enfim tudo que está relacionado ao espaço de ação, porque está relativizado à vontade dos espíritos. A quebra de algum valor cosmogônico significa "malefícios" para o divíduo e para o coletivo, portanto, é necessária a rigidez no cumprimento cosmogônico, pois consiste no atendimento aos espíritos norteadores da vida e da territorialidade.

Os valores cosmogônicos nos "marcadores territoriais" indígenas são imprescindíveis na organização do microcosmo e não devem ser considerados como crendices, folclores e mitos, devido estarem qualificados e permeados de memórias e experiências que transcendem a materialidade, antes se encontram construídos pela cosmogonia do coletivo e oferecem a explicação pela origem da vida e do próprio microcosmo em sua forma de representação organizativa. 
No contexto da espiritualidade, os "marcadores territoriais" transportam representações simbólicas qualitativas que se relacionam também nas expressões estéticas, além de outras, que contribuem para a compreensão não apenas da identidade, do pertencimento, do enraizamento étnico-coletivo, mas das experiências no espaço de ação, na territorialidade e na espiritualidade.

Em nossa análise, os coletivos carregam nos corpos "marcadores territoriais" de pertencimento de identificação, cuja apreensão consiste principalmente em rituais de passagens, e sua dimensão é a representação da cosmogonia herdada dos criadores de seus microcosmos, visto que se trata de valores com características subjetivas, intrassubjetivas e intersubjetivas, logo repletas de transcendentalidade.

Deste modo, entendemos que são valores acometidos de espiritualidade e incorporados simbólico e representativamente pelos divíduos em sua "fabricação de corpos", e envolvem os seres e não seres do microcosmo coletivo.

O sentido que afirmamos aqui assume forma simbólica com o contexto da espiritualidade, porque o "fabricar o corpo" consiste na renovação permanente em encontrar os espíritos no âmago das coletividades, considerando-se que cada divíduo transporta consigo uma multidão dentro de si, como condição de sua existência e de relacionamento com os demais. Esse caráter afere sua espiritualidade, sua territorialidade, seu pertencimento e sua identidade, porque ao representar objetiva e subjetivamente a si mesmo, também o faz coletivamente.

Por fim, o estudo da territorialidade indígena é possível a partir da abordagem fenomenológica, em que a espiritualidade é uma das passagens necessárias à compreensão do microcosmo, do modo de vida e da cultura de determinado coletivo, atribuindo-se ainda as experiências do/no espaço de ação. Neste tipo de análise, no entanto, carece da contribuição de outras áreas do conhecimento humano, em razão da complexidade apresentada. 


\section{Referências Bibliográficas}

ALMEIDA SILVA, Adnilson de. Territorialidades e identidade dos coletivos Kawahib da Terra Indígena Uru-Eu-Wau-Wau em Rondônia: "Orevaki Are" (reencontro) dos "marcadores territoriais". (Tese de Doutorado em Geografia). Curitiba: UFPR/SCT/DG/PPGMDG, 2010. 301 p.

Impactos Socioculturais em Populações Indígenas de Rondônia: estudo da Nação Jupaú. (Dissertação de Mestrado em Geografia). Porto Velho: PPGG/NCT/UNIR, 2007. 249 p.

. SILVA, J.C. Restabelecimento da Maloca Yñamõrarikãgã: um espaço de representação cultural do povo Jupaú. In: Anais do II Colóquio Nacional do Núcleo de Estudos em Espaço e Representações: espaços culturais: vivências, imaginações e representações/Instituto de Geociências, Mestrado em Geografia da UFBA, Departamento de Geografia da UFPR. Salvador: EDUFBA/NEER, 2007. V. II ed. p.1-17. Disponível também em http://www.geografia.ufpr.br/neer/NEER-2.

. GIL FILHO, S.F. \& SILVA, J.C. A territorialidade como construção do modo de vida e da identidade do povo indígena Jupaú. In: Anais do III SIMPGEO Simpósio Paranaense de Pós-Graduação em Geografia. Ponta Grossa: UEPG, 2008. V. 1. p. 34-45.

CASSIRER, E. Antropología Filosófica: Introdução a uma filosofia de la cultura. 5a ed. México: Fondo de Cultura Económica, 1968 [1944].

Ensaio sobre o homem: introdução a uma filosofia da cultura humana. São Paulo: Martins Fontes, 1994 [1944].

GALLOIS, D.T. Terras ocupadas? Territórios? Territorialidades? In: RICARDO, F. (org.) Terras indígenas e unidades de conservação da natureza: o desafio das sobreposições. São Paulo: Instituto Socioambiental, 2004. p. 37-41.

HURLEY, J. Itarãna (pedra falsa): lendas, mythos, itarãnas e folk-lore amazonicos. Separata do Vol. IX. Belém: Revista do Instituto Historico e Geographico do Pará/Off. Graphicas do Instituto D. Macedo Costa, 1934.

KRACKE, W.H. Ivaga'nga, Mbahira'nga e Anhang: gente do céu, gente das pedras e demônios das matas (espaço cosmológico e dualidade na cosmologia Kagwahiv). Comunicação apresentada no Grupo de Trabalho Cosmologia Tupi. Brasília: XVI Reunião da ABA, 1984.

LATOUR, B. Por uma antropologia do centro (entrevista do autor à revista). Mana 10(2), 2004. p.397-414.

Reassembling the social: An Introduction to Actor-Network-Theory. New York: Oxford University Press, 2005.

LEENHARDT, M. “J'ai um Corps: le nom et la personnalité”. In: LEENHARDT, M. Gens de la Grande Terre. Paris: Gallimard, 1937.

. La Persona a les Societats Primitives. Barcelona: Icaria, 1995. 
. Do Kamo: la persona y el mito en el mundo melanesio. Barcelona/Buenos Aires: Paidós, 1997.

LÓPEZ, E. Noções de Corporalidade e Pessoa entre os Jodï. Rio de Janeiro: MANA 12(2), 2006. p.359-388.

MATTA, R.A. Ensaios de antropologia estrutural. Petrópolis: Vozes, 1973.

MINDLIN, B. Índios. In: FUNARI, P.P. As religiões que o mundo esqueceu: como egípcios, gregos, celtas, astecas e outros povos cultuavam seus deuses. São Paulo: Contexto, 2009, p. 195-207.

MUMFORD, L. A cidade na história: Suas origens, transformações e perspectivas. São Paulo: Martins Fontes, 1991 [1961].

NUNES PEREIRA, M. Experiências e estórias de Baíra - o grande burlão. $4^{\text {a }}$ ed. Revista. Manaus: Academia Amazonense de Letras/Governo do Estado do Amazonas e Editora Valer, 2007 [1944].

PAIVA, J.O. RUPIGWARA: o índio kawahib e o conhecimento ativo nas diversas áreas de consciência. (Tese de Doutorado em Psicologia). São Paulo: USP/Instituto de Psicologia, 2005.

PEGGION, E.A. Relações em perpétuo desequilíbrio: a organização dualista dos povos Kagwahiva da Amazônia. (Tese de Doutorado em Antropologia). São Paulo: FLCH/DA/PPGAS/USP, 2005.

REALE, M. O Homem e seus horizontes. $2^{\underline{a}}$ ed. Rio de Janeiro: Topbooks, 1997.

SCHECHNER, R. Performance Theory. 2ª ed. London-New York: Routledge. 1988.

SEGALEN, M. Ritos e rituais contemporâneos. Rio de Janeiro: Editora FGV, 2002.

STRATHERN, M. O Gênero da Dádiva: problemas com as mulheres e problemas com a sociedade na Melanésia. Campinas: Editora Unicamp, 2006.

VAN GENNEP, A. Os rituais de passagem. Petrópolis: Vozes, 1978.

VIVEIROS DE CASTRO, E.B. A fabricação do corpo na sociedade xinguana e alguns aspectos do pensamento Yawalapíti (Alto Xingu): classificações e transformações. In: OLIVEIRA FILHO (Org.). Sociedades indígenas \& indigenismo no Brasil. Rio de Janeiro: Marco Zero, 1987. 